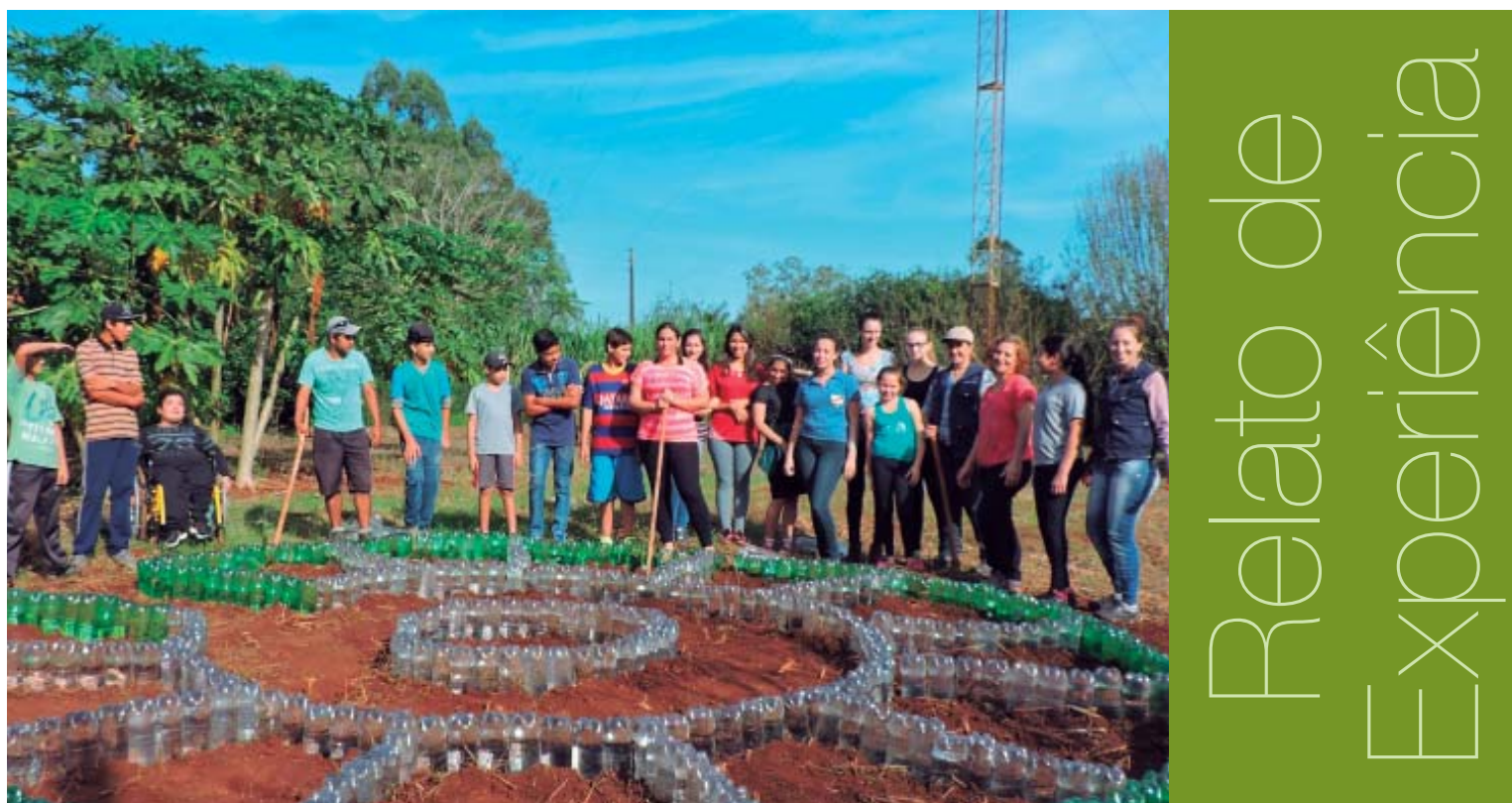

\title{
Horto medicinal: relógio do corpo humano ${ }^{1}$
}

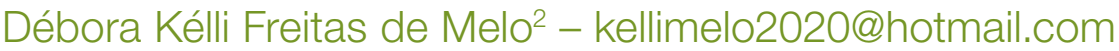 \\ Fernanda Kunz Griebeler ${ }^{3}$ - nandagriebeler@hotmail.com \\ Gabriela Lino Kleinubing ${ }^{4}$ - gabekleinubing@hotmail.com \\ Cleusa Inês Ziesmann ${ }^{5}$ - cleusa.ziesmann@uffs.edu.br
}

\section{RESUMO}

A atividade apresentada fez parte do componente curricular de Estágio Curricular Supervisionado II - Educação não Formal, do curso de Física - Licenciatura da Universidade Federal da Fronteira Sul (UFFS). 0 projeto foi desenvolvido na Escola Municipal de Ensino Fundamental Princesa Isabel, no município de Rolador/RS, com a intenção de: levar os alunos a compreender a importância da existência de um horto medicinal na escola e 0 uso de chás para melhorar a saúde; incentivar 0 uso de ervas medicinais; auxiliar a formação dos estudantes e da comunidade escolar em relação à educação ambiental e alimentar; levá-los a perceber a importância da prática da reciclagem. Este projeto possibilitou o desenvolvimento de diversas atividades interdisciplinares, unindo a teoria e a prática de forma contextualizada, o que auxiliou no processo de ensino e aprendizagem e no estreitamento das relaç̃̃es por meio da promoção do trabalho coletivo.

\section{PALAVRAS-CHAVE}

Educação ambiental. Interdisciplinaridade. Plantas medicinais.

\footnotetext{
1 Relato de experiência da disciplina de Estágio não formal da Universidade Federal da Fronteira Sul - Câmpus Cerro Largo.

2 Acadêmica do Curso de Física Licenciatura, UFFS, Câmpus Cerro Largo, Bolsista PROEXT/MEC/SESU - Formação Continuada Macromissioneira.

3 Acadêmica do Curso de Física Licenciatura, UFFS, Câmpus Cerro Largo, Bolsista PROEXT/MEC/SESU - Formação Continuada Macromissioneira
}

4 Acadêmica do Curso de Física Licenciatura, UFFS, Câmpus Cerro Largo, Bolsista do Programa Institucional de Bolsa de Iniciação à Docência - PIBID.

5 Doutoranda na PUCRS - Escola de Humanidades. Professora na Universidade Federal da Fronteira Sul - Câmpus Cerro Largo/RS. Pesquisadora do Grupo de Estudos e Pesquisa Educação e Violência (PUCRS) e no Grupo de Estudos e Pesquisa Direitos Humanos, Movimentos e Instituições da UFFS de Cerro Largo/RS 


\section{ABSTRACT}

The activity here presented was part of the curriculum component of Supervised Curricular Internship II - Non-Formal Education, Degree in Physics of the Federal University of the South Frontier (UFFS). The project was developed at the Municipal Elementary School of the Princesa Isabel, in the Municipality of Rolador/RS, aiming at: developing among students an understanding about the importance of the existence of a medicinal garden in the school and about the use of teas to improve health; encouraging the use of medicinal herbs; helping students and the school community in the development of knowledge related to environmental and food education; leading them to perceive the importance of recycling practices. This project has enabled the development of several interdisciplinary activities, combining the theory and practice in a contextualized manner, which aided the process of teaching and learning through the promotion of collective work.

\section{KEYWORDS}

Environmental Education. Interdisciplinarity. Medicinal Plants.

\section{Relato de experiência}

No Brasil, o conhecimento das propriedades das plantas medicinais é uma das maiores riquezas da cultura indígena, uma sabedoria tradicional que passa de geração em geração (PANIZZA, 2005). Porém, o uso inadequado dessas plantas pode trazer efeitos indesejáveis e, dessa forma, é necessário que conheçamos cada doença ou o sintoma, para escolher a planta certa a ser utilizada. Através da atividade realizada, pretendíamos divulgar a forma correta de utilização das ervas medicinais, o horário indicado para a ingestão de cada tipo de erva e seu benefício ao nosso corpo.

0 conhecimento sobre as plantas medicinais sempre tem acompanhado a evolução do homem através dos tempos. Remotas civilizações primitivas se aperceberam da existência, ao lado das plantas comestíveis, de outras dotadas de maior ou menor toxicidade que, ao serem experimentadas no combate às doenças, revelaram, embora empiricamente, o seu potencial curativo. (ARAÚJO, 2007, p. 45).

Velloso, Wermann e Fusiger (2005) ressaltam que esses conhecimentos passados de geração para geração persistem no tempo e são conservados pela população. A atividade chama-se "Horto Medicinal: Relógio do Corpo Humano", porque cada parcela corresponde ao intervalo de uma hora e também representa um órgão do corpo humano. Nessas parcelas são cultivadas as plantas medicinais que auxiliam a amenizar as dores ou transtornos de saúde do órgão representado.

Objetivamos com essa atividade que os alunos entendessem a importância do cultivo de um horto medicinal na escola e do uso de chás para melhorar a saúde, incentivando-os a buscar alternativas mais saudáveis. Dessa forma, estimulamos principalmente 0 uso de chás e a prática da reciclagem, por meio, por exemplo, do reaproveitamento de garrafas pet, priorizando e incentivando, ao mesmo tempo, o trabalho em grupo.

\section{Metodologia}

0 trabalho foi realizado na Escola Municipal de Ensino Fundamental Princesa Isabel, localizada na comunidade de Igrejinha, interior do Município de Rolador/RS, que apresenta oferta de ensino da Educação Infantil ao $9^{\circ}$ ano. A escola abriga 53 alunos, sendo 40 alunos matriculados nos anos iniciais do ensino fundamental, nos turnos matutino e vespertino, e conta com um total de treze professores. Possui também uma merendeira e uma agente de limpeza. Os alunos vêm de comunidades vizinhas, da cidade de Rolador e também da própria comunidade de Igrejinha. Todos dispõem de transporte escolar, que é disponibilizado gratuitamente pela prefeitura municipal de Rolador.

A demarcação e montagem do horto medicinal teve 0 auxílio dos estudantes e dos professores, com a divisão dos alunos em dois grupos. Um grupo enchia as garrafas pet de água e 0 outro realizava a sua contagem e lavagem. Os recursos materiais utilizados foram: adubo, ancinho (rastelo), carrinho de mão (pedreiro), enxada, estacas e barbantes, luvas, mangueiras, marreta pequena (martelo), pá comum, pazinha larga com cabo de madeira, peneira, picareta, placa de identificação e regadores. 
Para a confecção das plaquinhas resolvemos reaproveitar as costaneiras e uma repartição de madeira que havia sido jogada fora. As mudas de chás foram trazidas pelos alunos, professores da escola e pela Empresa de Assistência Técnica e Extensão Rural (EMATER). Foram realizados 12 encontros, uma vez por semana.

Durante o período de construção do horto, foi necessário repensar as medidas que havíamos planejado, visto que deveriam possibilitar o acesso para deficientes físicos, já que um dos alunos envolvidos apresentava essa particularidade. Após essas mudanças realizadas, iniciamos a organização e a confecção das placas de identificação de cada espécie de chá que iríamos plantar, bem como a identificação das plantas com as orientações do horário em que deveriam ser ingeridas e a sua função, conforme orientações trazidas pela equipe da EMATER.

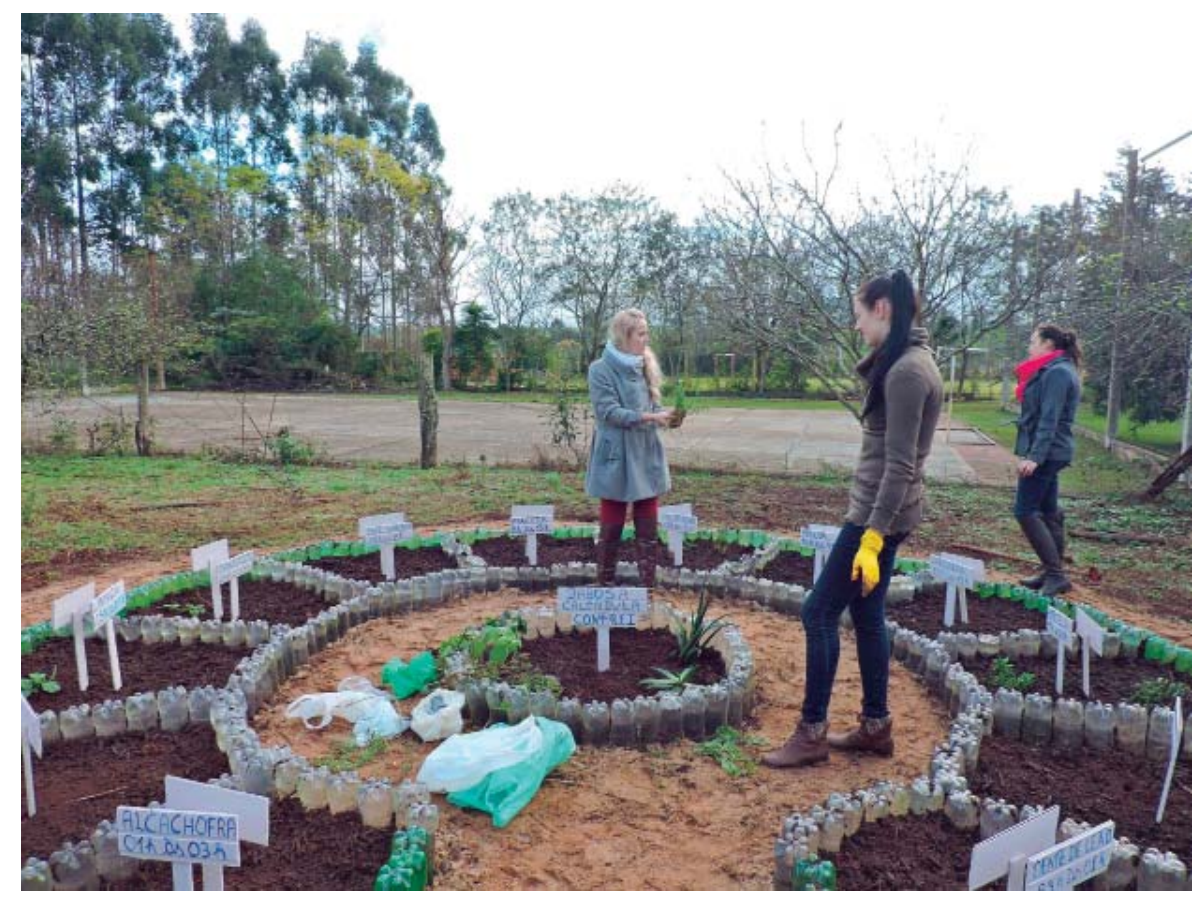

Figura 1: Plantio

Fonte: Dados da pesquisa.

\section{Resultados e discussão}

0 objetivo principal de nossa proposta de estágio era de promover a educação em saúde e meio-ambiente, preservação ambiental e alimentação saudável através de atividades específicas sobre o funcionamento dos órgãos do corpo humano, fazendo assim uma reflexão sobre os hábitos alimentares, as escolhas comportamentais e os cuidados básicos de saúde, utilizando e identificando as plantas medicinais com segurança.

Segundo Sacramento (2001), a fitoterapia, no Brasil, resistiu devido às raízes profundas na consciência popular, que reconhece sua eficácia e legitimidade. 0 conhecimento proveniente de gerações anteriores necessita ser conservado, porém é importante destacar que as pessoas que detêm esse conhecimento são aquelas com idade superior a 60 anos e nível de escolaridade mais baixo, ao passo que as pessoas mais jovens e com nível de escolaridade mais elevado se mostram pouco interessadas na fitoterapia.

0 governo federal aprovou a Política Nacional de Plantas Medicinais e Fitoterápicos por meio do Decreto $n^{0} 5813$ de 22 de junho de 2006, que trata, de maneira geral, das políticas públicas de saúde, meio-ambiente, desenvolvimento econômico e social com o intuito de gerar ações que venham a beneficiar a melhoria da qualidade de vida de toda a população brasileira.

Dessa forma, o horto foi construído com garrafas pet, atribuindo ao projeto a prática da reciclagem, para que os alunos pudessem compreender, na prática, a importância da reutilização de materiais que até então tinham como único e exclusivo destino o lixo. Segundo Carvalho (2005), a reciclagem gera economia de matéria-prima e energia, bem como diminui a quantidade de lixo jogada na natureza e em aterros sanitários. 
Figura 2: Grupo de alunos envolvido no projeto.

Fonte: Autoria própria.

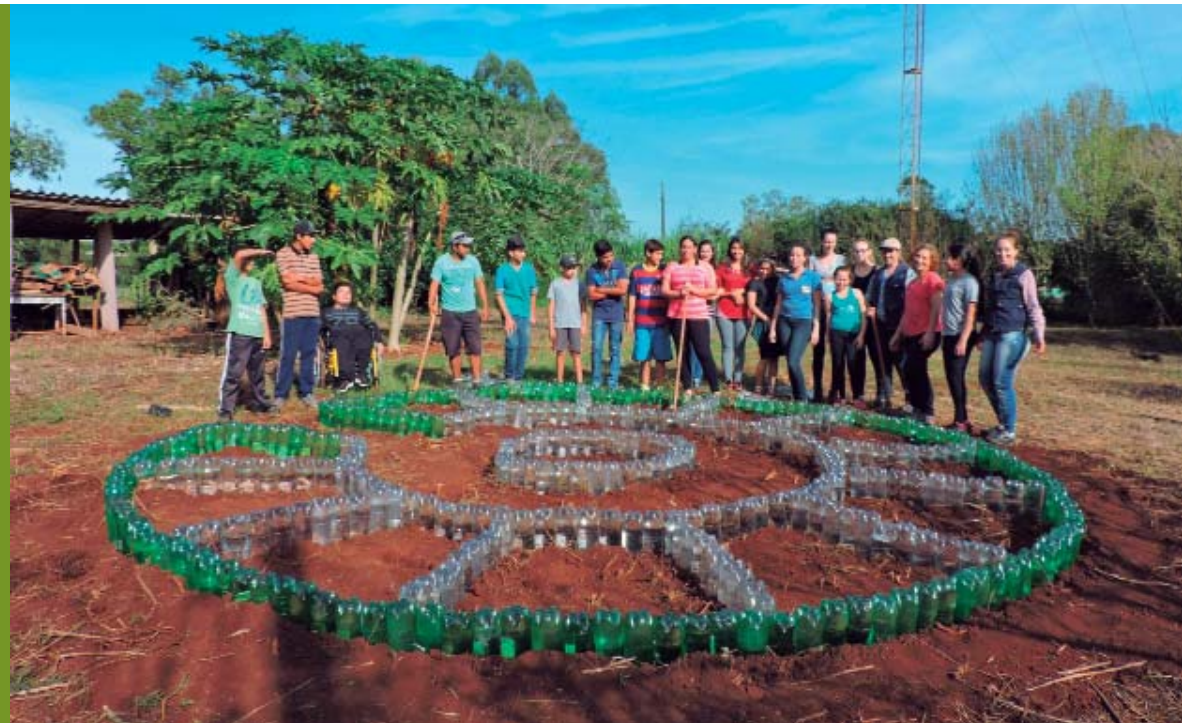

Para Araújo (2007), o conhecimento das propriedades de plantas medicinais é uma das maiores riquezas da cultura indígena, uma sabedoria tradicional que passa de geração em geração e, portanto, é necessário que seja estudada por nós, uma vez que pode resultar em benefícios para a nossa saúde. Ainda, para auxiliar nessa tarefa, foi organizado um cartaz com os alunos para que eles pudessem ter o conhecimento sobre o horário adequado para uso dos chás, bem como sobre qual planta medicinal pode ajudar no atendimento da necessidade de cada um.

Figura 3: Horto Medicinal.

Fonte: Autoria própria.

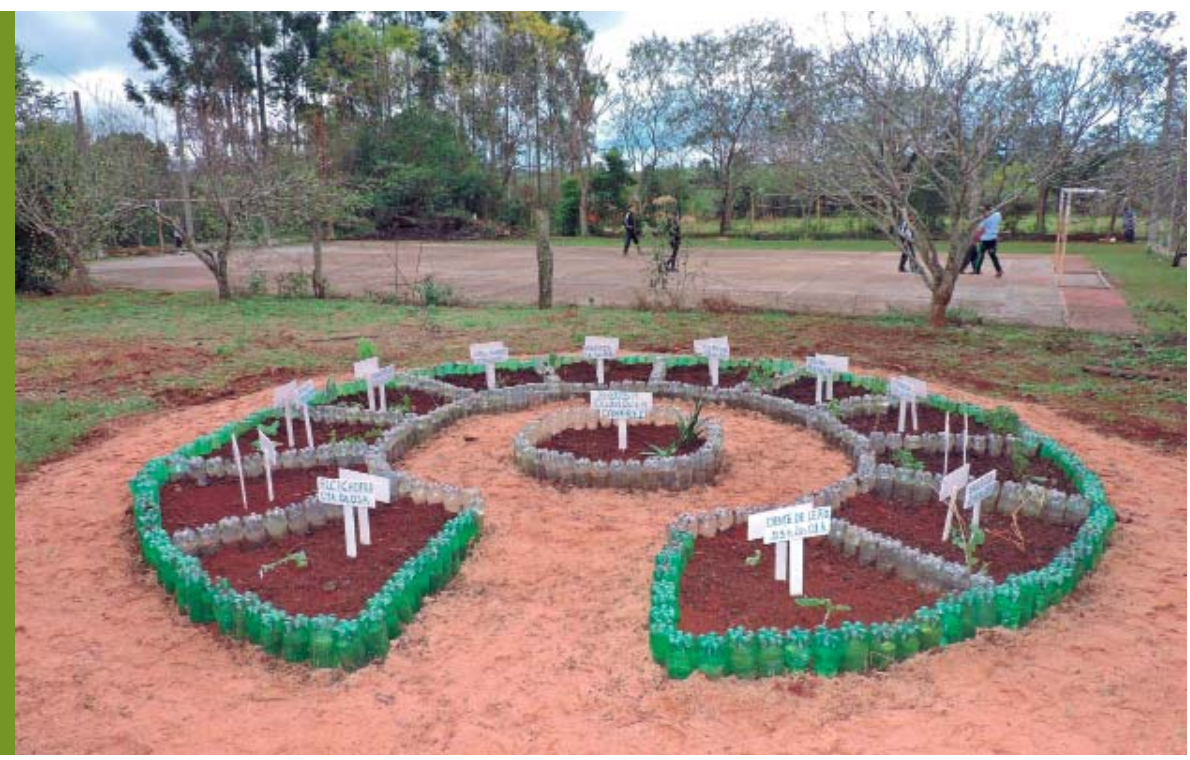

Durante a realização deste projeto, pudemos perceber que os alunos estiveram entusiasmados em participar de todas as atividades, sempre fazendo o melhor para a sua escola. Consideramos que executar este projeto juntamente com alunos e professores foi fundamental para a formação dos alunos, pois foram trabalhados conceitos sobre as práticas de reciclagem e reutilização dos materiais, trabalho em grupo, organização, questões ecológicas e alimentação saudável.

\section{Considerações finais}

Através da realização deste projeto, percebemos que a educação não formal realizada com atividades planejadas e direcionadas contribuiu para a formação humana dos educandos e para o seu aprendizado. Este estágio nos trouxe uma experiência gratificante, pois nós tivemos a oportunidade de aprender sobre qual seria a melhor forma de trabalhar e transmitir conhecimentos sobre a importância do uso de chás, tanto em casa como na escola, e sobre 0 
benefício dessa prática para a nossa saúde. Ao mesmo tempo, vimos a necessidade de enfatizar a importância de reutilizarmos materiais como as garrafas pet para construção do horto, no nosso caso, ou ainda para o embelezamento de jardins.

Esperamos que esse horto seja útil para a comunidade escolar, que os educandos tenham entendido a importância da interdisciplinaridade e que precisamos cuidar da nossa saúde e saber reutilizar produtos - nem tudo precisa converter-se em lixo, precisamos ter consciência disso. 0 que motiva o nosso grupo é o fato de que, mesmo após a conclusão do projeto, o que foi realizado continuará beneficiando a escola.

\section{Referências}

ARAÚJO, E.C. Use of medicinal plants by patients with cancer of public hospitals in João Pessoa (PB). Revista Espaço para a Saúde, v. 8, n. 2, p. 44-52, 2007.

BRASIL. Política Nacional de Plantas Medicinais. DECRETO № 5.813, DE 22 DE JUNHO DE 2006. Disponível em: <http://www.planalto.gov.br/ccivil_03/_Ato2004-2006/2006/Decreto/ D5813.htm>. Acesso em: 28 jun. 2017.

CARVALHO, Julia Maria Gomes. Vida e lixo: a situação de fragilidade dos catadores de material reciclável em Marilia e os limites da reciclagem. Anais do $6^{\circ}$ Seminário do Trabalho. 2005. Disponivel em: <http://www.estudosdotrabalho.org/anais6seminariodotrabalho/ juliamariagomescarvalho.pdf>. Acesso em: 25 jun. 2017.

PANIZZA, S. Ensinando a cuidar da saúde com as plantas medicinais: Guia prático de remédios simples da natureza. São Paulo (SP): Prestígio; 2005.

SACRAMENTO, H. T. Legislação para produção, comercialização e uso de plantas medicinais. In: Jornada Paulista de Plantas Medicinais, 5; 2001. Botucatu. Anais.

VELLOSO, Caroline Crochemore; WERMANN, Afaf Muhhammad; FUSIGER, Teresinha Berwian. Horto Medicinal Relógio do Corpo Humano. EMATER: ASCAR, Putinga/RS. p.1-14, 2005. Disponível em: <http://www.biodiversidade.rs.gov.br/arquivos/1159290630estudo_caso_ HORTO_MEDICINAL_RELOGIO_DO_CORPO_HUMANO.pdf>. Acesso em: 31 mar. 2016. 